\title{
Slavernijonderwijs in de praktijk, wat gebeurt er in de klas? Een pleidooi voor meer aandacht voor de erfenis van het slavernijverleden
}

\author{
Aspha Bijnaar
}

Als op een middelbare school in 's-Hertogenbosch de docent geschiedenis aankondigt dat ze binnenkort klassikaal de documentaire Wit is ook een kleur van Sunny Bergman gaan bekijken en bespreken, loopt Tulah naar voren om de juf te vragen of ze dan de klas uit mag, omdat ze de documentaire niet met de klas wil bekijken. $\mathrm{Na}$ doorvragen vertelt ze de juf, met enige schroom, dat ze als enige zwarte in de klas regelmatig het mikpunt is van opmerkingen over haar Zuid-Afrikaanse cultuur en huidskleur, vooral na lessen of klasgesprekken over beladen onderwerpen. De docent, getroffen door dit relaas, heeft toen samen met Tulah een geschiedenisopdracht ontwikkeld voor de school die het bespreken van gevoelige onderwerpen beter mogelijk maakt ${ }^{1}$. Een doorbraak voor Tulah, die zich hierdoor meer begrepen en gerespecteerd voelt door haar medescholieren.

Soortgelijke gevoelens van ongemak hoor ik vaker tijdens lessen over slavernij, discriminatie, beeldvorming of stereotypering of bij klasgesprekken over het Sinterklaasfeest op basis- en middelbare scholen. Scholieren van kleur met Afrikaanse of Caraïbische roots worden ronduit geplaagd met de woorden neger, slaaf of Zwarte Piet, of er worden andere grappen gemaakt over hun uiterlijk, waardoor ze zich gekwetst voelen. Een paar voorbeelden uit de klas. Zo hoort een zwarte docent die het onderwerp beeldvorming en stereotypering bespreekt, meisjes in de klas giechelen over dat de personen uit het bijbehorende beeldmateriaal toch 'echt net apen zijn, gewoon negers'. Op een andere school verklaart een leerling na de meivakantie de afwezigheid van medeleerling Jerry met de woorden 'die is nog bananen aan het plukken in het oerwoud'. Weer een andere docent hoort een leerling zeggen dat bruine kinderen een 'poepkleur' hebben. Dit alles naast opmerkingen over 'stinkende moslima's' die zich tijdens hun menstruatie niet zouden mogen wassen vanwege hun geloof, of over homoseksuelen die hier niet thuishoren.

Als het aan deze kinderen ligt, worden zulke lessen liever niet gegeven. Maar hiermee lijkt zich iets paradoxaals te voltrekken. Enerzijds is er de roep om meer aandacht voor bijvoorbeeld slavernijgeschiedenis in het onderwijs, met name als exa-

* Dr. Aspha Bijnaar is onafhankelijk onderzoeker en directeur van stichting EducatieStudio. Ze is in 2002 als sociologe gepromoveerd aan de Universiteit van Amsterdam en heeft als onderzoeker gewerkt aan diverse wetenschappelijke publicaties, tentoonstellingen en lespakketten over slavernij en het erfgoed van slavernij. Ze ontwikkelde een reeks gastcolleges met theater over slavernijgeschiedenis en erfenis getiteld Hedendaags burgerschap, slavernij en jij!. Daarnaast maakte ze de theatervoorstelling Rebelse Vrouwen. Een voorstelling over verzet van vrouwen in slavernij en gaf ze een stripboek uit, getiteld Jacquelina. Slavin van Plantage Driesveld. 
menonderwerp; anderzijds is er een groot ongemak bij scholieren van kleur tijdens zo'n les.

Tegelijk groeit het aantal docenten dat ongemak ervaart tijdens de behandeling van gevoelige historische en maatschappelijke onderwerpen, zoals de trans-Atlantische slavenhandel en slavernij, de acties in de Indonesische onafhankelijkheidsoorlog, de Tweede Wereldoorlog, het Israëlisch-Palestijnse conflict, lhbt (lesbisch, homoseksueel, biseksueel en transgender), religie, Sinterklaasfeest. Diverse organisaties springen hierop in door docenten trainingen aan te bieden, opdat ze toegerust met de noodzakelijk skills moeilijke situaties in de klas aankunnen. Organisaties die zulke trainingen verzorgen, zijn onder andere Dander, Critical Mass, het Anne Frankhuis en School en Veiligheid.

Het ongemak bij zowel scholieren (van kleur) als bij de docenten komt mijns inziens voort uit een gebrek aan historisch besef. Door dit gebrek krijgen negatieve opmerkingen alle ruimte in de schoolsetting. Ik denk dat deze ongemakken beter te voorkomen zijn als er al vroeg in het onderwijs meer en structurele aandacht besteed wordt aan vooral de erfenis van het trans-Atlantische slavernijverleden. Als scholieren leren over de geschiedenis en daarmee de erfenis van die geschiedenis goed uitgelegd krijgen, creëren we goed ingevoerde jonge burgers die vanuit begrip en respect hun standpunt leren bepalen en hun gedrag daarop aanpassen. Hoe kunnen scholen dit aanpakken? Dit artikel is een aanzet hiertoe.

Een van de manieren waarop scholen hiermee omgaan, is met het aanbieden van weerbaarheidstrainingen voor docenten. Ik ben geen docent, maar ben wel actief op het gebied van educatie en slavernij. Vanuit die hoedanigheid heb ik een aantal weerbaarheidstrainingen voor docenten bijgewoond en ondergaan, voornamelijk als onderzoeker en aanschouwer. Centraal in zulke trainingen staat de vraag hoe docenten om kunnen gaan met moeilijke geschiedenis of lastige situaties in de klas: hoe kunnen ze omgaan met het onbehagen dat het bij hen zelf oproept? Tijdens de trainingen wordt gebruikgemaakt van de eigen ervaringen van de docenten en oefenen ze met de skills die ze tijdens de training aangereikt krijgen.

Docenten leren bij de trainingen dat er drie gangbare reacties zijn. ${ }^{2}$ De docent reageert afwijzend op de opmerking en stuurt de leerling de klas uit; de docent slaat geen acht op de opmerking en gaat door met de les; of de docent gaat een betekenisvol gesprek aan met de leerling en de overige leerlingen uit de klas. De training richt zich vervolgens op deze laatste reactie. In een rollenspel met een trainingsacteur kunnen de deelnemers hiermee oefenen.

Ik trof gemiddeld vijftien deelnemers bij de bijeenkomsten waar ik getuige van was. Deze docenten zijn over het algemeen betrokken en gemotiveerd en willen graag beter toegerust zijn om in de klas moeilijke gesprekken met leerlingen te voeren.

Een centraal onderdeel van de cursus is het rollenspel met de trainingsacteur. Ik denk dat bij een aantal deelnemers nog een wereld te winnen is bij het inzetten van de juiste toon, lichaamstaal en formuleringen als ze het gesprek aangaan in de klas. Maar dat is een kwestie van ervaring, die kan worden opgedaan als de trainingen structureel aan leraren worden aangeboden of ingebed worden in de curricula van docentenopleidingen. Het algemene bereik van deze trainingen, en in hoeverre de trainingsvaardigheden vruchten afwerpen, moet nog nader onder- 
zocht worden. Nuttig en noodzakelijk zijn deze trainingen zeker, maar ik zal hieronder betogen dat weerbaarheidstrainingen alleen niet voldoende zijn.

\section{Bewustwording van de erfenis}

Dat docenten anno 2019 nog steeds worstelen met lessen en gesprekken in de klas over 'gevoelige onderwerpen' komt mijns inziens voort uit het feit dat er onvoldoende informatie en erkenning is over moeilijke geschiedenissen en hun nasleep in de samenleving. Het voortwoekeren van lastige situaties in de klas vindt een vruchtbare bodem in klassen van docenten met onvoldoende kennis over het trans-Atlantische slavernijverleden van Nederland en, maar vooral, over de erfenis hiervan. Deze erfenis moeten we eerst erkennen, opdat het in de klassen gemakkelijker bespreekbaar wordt gemaakt. We hebben hierin nog een lange weg te gaan.

Een deel van die lange weg moet mijns inziens gezocht worden in het creëren van bewustwording, in een zo vroeg mogelijk stadium, over de 'gevoelige' hoofdstukken van de vaderlandse geschiedenis en dat de gevolgen van die geschiedenis zichtbaar en voelbaar zijn in ons dagelijkse leven. Als jongeren vroeg in het onderwijs hiermee in aanraking komen, kunnen ze zich hier rekenschap van geven in hun weg naar volwassenheid. Die vroege mogelijkheid biedt de onderwijscanon, de Canon van Nederland (www.entoen.nu), waar slavernij een van de vijftig vensters is. Voor het primair onderwijs bijvoorbeeld is door deze canon de Vensterles getiteld 'Slavernij' gemaakt.

\section{Slavernijlessen op de basisschool}

De Canon van Nederland voorziet in een 'Vensterles Slavernij' die gaat over het trans-Atlantische slavernijverleden van Nederland. Deze Vensterles is gemaakt voor de groepen 5 tot en met 8 van het basisonderwijs. Het beschikbare materiaal van deze les voorziet in een vensterplaat, een werkblad en een docentenhandleiding en is gratis te downloaden via www.entoen.nu, meer specifiek via www. entoen.nu/nl/slavernij/lessen/vensterles-slavernij. De les behandelt de hoofdlijnen van deze geschiedenis. De leerlingen leren dat Nederlandse kooplieden en de West-Indische Compagnie betrokken waren bij de handel in goederen en 'slaven', een handel die via de trans-Atlantische driehoekshandel werd gereguleerd. De 'slaven' werden in Afrika gekocht van Afrikaanse stamhoofden en in schepen vervoerd naar plantages in de Nederlandse koloniën om daar een leven te leiden van hard werken. Ze leren dat brandmerking en ketens werden gebruikt om ontsnappingen te voorkomen, dat 'slaven' de plantages ontvluchtten en diep in de bossen zelfstandige leefgemeenschappen vormden. Ook leren ze dat de slavernij uiteindelijk werd afgeschaft op 1 juli 1863, maar dat Nederland daarin niet vooropliep. Tot slot leren ze dat het Nationaal Monument Slavernijverleden en de jaarlijkse herdenking en viering, het Keti Koti-festival, in het Amsterdamse Oosterpark ons herinneren aan deze geschiedenis. 
Echter, de weergave van het Nederlandse slavernijverleden in deze Vensterles schiet tekort: de les geeft een oppervlakkig beeld van de historische werkelijkheid in die periode. Het verhaal beperkt zich tot de economische en politieke kanten van de slavernij, waarbij de vragen waar, wie, wanneer, wat en hoe in vogelvlucht worden behandeld. Dit alles wordt neutraal gepresenteerd, zonder morele afwijzing. Ofwel, de waarom-vraag wordt niet gesteld. Er wordt niet besproken dat slavernij banale mensenhandel was, waar Nederlandse kooplieden rijk van wilden worden; dat de vrijheid en identiteit van onschuldige Afrikaanse mannen, vrouwen en kinderen met grof geweld werden ontnomen door hen tot slaaf te maken; dat hun verdere leven, en vele generaties na hen, in het teken zou staan van lichamelijk mishandeling en geestelijke vernedering; dat ze voortdurend snakten naar en vochten voor hun vrijheid die hen bruut was ontnomen; dat hun uiterlijk, de identiteit en het geloof daarbij inferieur zijn gemaakt met als doel de superioriteit van de witte westerse mens en zijn cultuur daar boven te stellen. Nergens in de tekst van de Vensterles wordt expliciet gemaakt dat dit laatste aspect van de slavernij vandaag de dag nog voortduurt in onze alledaagse werkelijkheid, in de vorm van hardnekkige stereotypering, vooroordelen, racisme en discriminatie jegens zwarte mensen.

Daarnaast presenteert de Vensterles een vertekend beeld. Een van de bijbehorende opdrachten illustreert dit. 'Hoe kwamen de kooplieden aan slaven?' wordt er gevraagd. De bijbehorende docentenhandleiding vermeldt dat het antwoord moet zijn: 'Ze kochten ze van Afrikaanse stamhoofden.' Dat Nederlandse kooplieden 'slaven' kochten van Afrikaanse stamhoofden is niet geheel onwaar, maar deze formulering suggereert een eerlijke en langdurige handelsrelatie waarin ongelijkheid, misleiding, ronselpraktijken noch geweld plaatsvonden. Het tegendeel is waar (Postma, 2008; Davis, 2006).

Kortom, de Vensterles uit de Canon van Nederland is inhoudelijk onvoldoende ontoereikend, geeft op punten een vertekend beeld en rept met geen woord over de verwerpelijke erfenis van racisme en discriminatie. Echter, de meeste leerkrachten die ik tegenkom zijn geen experts op het gebied van slavernijgeschiedenis, waardoor ze in eerste instantie zijn aangewezen op deze Vensterles, al dan niet aangevuld met andere bronnen. Zolang de Canon van Nederland deze beperkingen kent, zullen scholen die dat inhoudelijk anders willen hun voordeel moeten doen met initiatieven uit het veld. Er zijn in de loop der tijd diverse lespakketten gemaakt door (zelf)organisaties. Slechts een heel klein deel daarvan is te vinden op www.lesmateriaalslavernijverleden.nl, waarvan het merendeel is bestemd voor het voortgezet onderwijs. Voor het primair onderwijs zijn dus vergelijkenderwijs nog maar weinig alternatieven ontwikkeld.

Vanaf 2013 ben ik vanuit EducatieStudio bezig met het bespreken van de gevoeligheden rondom slavernij en haar erfenis op basisscholen in de vorm van gastcolleges met theater. Dit project is getiteld 'hedendaags burgerschap, slavernij en jij!' (met theater) en wordt sinds twee jaar financieel ondersteund door de gemeente Amsterdam.

Inhoudelijk opereert dit project binnen de kaders van 'hedendaags burgerschap en sociale cohesie'. In 2005 is namelijk een onderwijswet aangenomen die scholen vraagt aandacht te besteden aan 'actief burgerschap en sociale integratie'. Cen- 
traal daarin staat 'de bereidheid en het vermogen om deel uit te maken van de gemeenschap en daar een actieve bijdrage aan te leveren'. ${ }^{3}$ Burgerschap is ook opgenomen in de kerndoelen van het primair onderwijs. 'Hedendaags burgerschap, slavernij en jij!' zoekt aansluiting bij deze onderwijswet.

\section{Twee gastcolleges: historische college of de actualiteit}

'Hedendaags burgerschap, slavernij en jij!' is een interactieve werkvorm, gecombineerd met een powerpointpresentatie met prikkelend beeldmateriaal. In een theatervoorstelling in de klas aan de hand van persoonlijke verhalen en lotgevallen van kinderen in slavernij gaan we met de kinderen in gesprek over de geschiedenis en erfenis van ons slavernijverleden.

Scholen kunnen kiezen uit twee colleges met theatervoorstelling. Het eerste college gaat in op de geschiedenis van het Nederlandse slavernijverleden. De nadruk ligt op het verleden: wanneer en waarom was er slavernij, hoe zag het leven eruit op de plantages, waren er ook kinderen in slavernij, en wat moesten zij doen op de plantage? Tot slot wordt besproken welke sporen dit heeft nagelaten in onze samenleving.

Het tweede college bespreekt de actualiteit van slavernij: de erfenis van ons Nederlandse slavernijverleden. De nadruk ligt op de actualiteit, het nu. Dit college voert langs sporen in de openbare ruimte, zoals de gouden koets, het Paleis op de Dam, het Sinterklaasfeest, het Museumplein, culinair, taal, mode en cultuur.

EducatieStudio heeft inmiddels tientallen scholen bezocht om gastlessen te verzorgen voor de bovenbouw. De belangrijkste doelgroepen zijn de groepen 7 en 8 , maar sinds kort heb ik op verzoek van scholen ook gastcolleges ontworpen en gepresenteerd voor leerlingen uit de groepen 5 en 6 . De bezoeken aan deze scholen geven een inkijkje in hoe leerkrachten op de basisschool zelf lessen over slavernij vormgeven. Voordat ik een school aandoe met onze gastcolleges, wil ik namelijk eerst weten of het onderwerp slavernij al aan bod komt in de klas, in hoeveel uren, binnen welke vakgebieden en met welk (les)materiaal. Informatie hierover komt in eerste instantie van de leerkrachten zelf, via de gesprekken die ik met hen voeren, maar ook via de evaluatieformulieren die ze invullen. Vanwege de privacy blijven de namen van de scholen en van de leerkrachten onvermeld in dit artikel.

Van alle klassen die ik in de loop der jaren heb bezocht, had een kleine meerderheid van de leerkrachten de onderwerpen slavernij en slavenhandel reeds behandeld. In de overige klassen was het onderwerp nog niet aan bod gekomen. Uit de evaluatieformulieren blijkt dat juist deze leerkrachten hun groep 7 - soms in combinatie met groep 8 - het gastcollege hebben laten volgen, waardoor de kinderen van deze scholen via 'Hedendaags burgerschap, slavernij en jij!' voor het eerst les kregen over slavernij. Deze gastcolleges vormen klaarblijkelijk een welkome introductie op de lessen slavernij die nog behandeld zullen worden.

De leerkrachten die wel al les hadden gegeven over de slavernij, waarderen deze gastcolleges vanwege de historische verdieping, de aansluiting met het actuele debat, de details of de persoonlijke verhalen uit deze geschiedenis. 
De leerkrachten die reeds lessen over slavernij hadden verzorgd, besteedden er 1,5 tot 4 lesuren per jaar aan. Maar we telden ook uitschieters: een leerkracht meldde dat hij per jaar zeker meer dan 10 uur aan het onderwerp besteedt. Een andere leerkracht van een andere school gaf aan geen vast aantal uren aan slavernij te besteden, maar: 'wel regelmatig, zodra de actualiteit er om vraagt krijgt het onderwerp weer aandacht in de klas'.

Het vak of kader waarbinnen de leerkrachten slavernij en slavenhandel behandelen is geschiedenis, levensbeschouwing of wereldoriëntatie. Leerkrachten die deze kaders niet noemden, zeiden dat ze het aanbieden als 'Project slavernij' of als een extra les.

Het lesmateriaal dat de leerkrachten op school gebruiken, bestaat uit methoden als 'Reis door de tijd', 'Wijzer door de Tijd', 'Klassenbox' en 'Brandaan'. In al deze documenten wordt de geschiedenis van slavernij en slavenhandel behandeld in grote hoofdlijnen. Uitleg over de doorwerking van dat verleden komt er nauwelijks of niet in voor. Daarnaast maken veel leerkrachten gebruik van televisieprogramma's, televisieseries, websites, films of boeken. Specifiek noemden ze de televisieserie Roots, relevante afleveringen van Klokhuis en Schooltv, de websites www. entoen.nu en www.slavernijenjij.nl, een bezoek aan het Tropenmuseum, tentoonstellingsprogramma's van musea over de Gouden Eeuw of over de trans-Atlantische slavernij, boeken, en eigen kennis van de leerkracht, die daarvoor verschillende bronnen raadpleegt.

De erfenis van het slavernijverleden komt nauwelijks tot niet aan bod in de lesmethoden. Of het toch in de klas wordt besproken, is afhankelijk van de leerkracht: de ene behandelt het wel, de andere niet. Het is maar net hoe de leerkracht ervoor staat. De gastcolleges 'Hedendaags burgerschap, slavernij en jij!' gaan juist uitgebreid in op de gevolgen van ons slavernijverleden. Dit onderdeel maakt de lessen noodzakelijk en spannend.

Ik denk dat deze aanpak werkt. We krijgen achteraf van de leerkrachten mee dat de leerlingen nog lang hebben nagepraat over de gastlessen. Een van de leraren gaf achteraf aan dat de kinderen erg onder de indruk waren van informatie over de Wereldtentoonstelling van 1883, 'toen Javaanse mensen werden tentoongesteld op het Museumplein. De meeste kinderen wisten niet dat dit vroeger op deze plek heeft plaatsgevonden.' De positieve evaluaties van de gastcolleges geven mij de indruk dat de aanpak werkt: het zorgt voor meer begrip en bespreekbaarheid van deze onderwerpen.

\section{Vuistregels voor de toekomst}

Wat kunnen scholen doen om beladen historische of maatschappelijke onderwerpen beter bespreekbaar te maken in de klas? Ten eerste, het behandelen van de erfenis van de geschiedenis van slavernij. Dit kan in een vroeg stadium in het onderwijs, dus al vanaf groep 5 op de basisschool. Dat draagt bij aan de ontwikkeling van het bewustwordingsproces. Ten tweede moet het lesmateriaal over deze geschiedenis eenduidig zijn. De 'Vensterles Slavernij' van de Canon van Nederland op www.entoen.nu, waar veel docenten vooreerst hun toevlucht toe zoeken, 
behoeft verbetering. Deze Vensterles moet inhoudelijk verbeterd worden op de punten die hierboven zijn aangegeven. Daarnaast moet deze les expliciet maken dat slavernij moreel verwerpelijk is, en dat het een erfenis heeft voortgebracht die deel uitmaakt van onze alledaagse werkelijkheid. Daartoe is noodzakelijk dat leerkrachten gedegen lesmateriaal krijgen aangereikt. Nu gaan ze zelf sprokkelen naar aanvullend materiaal, waarvan niet voor elke docent helder is wat de status is van het zelf bij elkaar gezochte materiaal. Ten vierde moeten trainingen over hoe een moeilijk onderwerp klassikaal te bespreken structureel, dus jaarlijks worden opgenomen in de nascholingsprogramma's voor docenten. Alleen dan zullen jongeren als Tulah zich in de toekomst niet zo vervreemd en onbegrepen voelen wanneer de docent de moeilijke bladzijden uit onze vaderlandse geschiedenis behandelt.

\section{Noten}

1 Bijnaar, A. (2017). Lespakket Afrispectives. Een klein lespakket over Afrika, haar diaspora, diversiteit en identiteit. www.afrispectives.com/toolkit/.

2 Zie hiervoor Brandsma, B. (2016), Polarisatie. Inzicht in de dynamiek van wij-zij denken, Uitgeverij BB in Media

3 Zie hiervoor Bron, J. (2006). Een basis voor burgerschap. Een inhoudelijk verkenning voor het funderend onderwijs. Stichting Leerplan Ontwikkeling (SLO).

\section{Literatuur}

Bijnaar, A. (2017). Lespakket Afrispectives. Een klein lespakket over Afrika, haar diaspora, diversiteit en identiteit.www.afrispectives.com/toolkit/.

Brandsma, B. (2016), Polarisatie. Inzicht in de dynamiek van wij-zij denken, Uitgeverij BB in Media Bron, J. (2006). Een basis voor burgerschap. Een inhoudelijk verkenning voor het funderend onderwijs. Stichting Leerplan Ontwikkeling (SLO).

Canon van Nederland. Slavernij - Vensterles. www.entoen.nu/nl/slavernij/lessen/vensterles -slavernij.

Davis, D.B. (2006). Inhuman Bondage. The Rise and Fall of Slavery in the New World. Oxford: Oxford University Press.

Postma, J. (2008). The Dutch in the Atlantic Slave Trade. Cambridge: Cambridge University Press.

Slavernij en Jij (2013). www.slavernijenjij.nl.

Stichting EducatieStudio. 2017. www.educatiestudio.com. 